\title{
Controversies about sugars consumption: state of the science
}

\author{
James M. Rippe $\mathrm{e}^{1,2,3} \cdot$ Ascensión Marcos $^{4}$
}

Received: 26 February 2016 / Accepted: 8 May 2016 / Published online: 20 June 2016

(C) The Author(s) 2016. This article is published with open access at Springerlink.com

\begin{abstract}
Introduction Few topics in nutrition generate more controversy and debate than the putative associations between added sugars and health. With this as background, a group of researchers in the area of sugars and health gathered at the European Nutrition Conference (FENS) in 2015 to discuss these controversies and provide evidence-based science. The purpose of the current article was to provide a brief summary of some of the highlights from each of the presenters and serve as an Introduction to the supplement which contains full articles based on their presentations.
\end{abstract}

Keywords Sucrose $\cdot$ High-fructose corn syrup $\cdot$ Isoglucose

Nutrition and health throughout life-cycle-Science for the European consumer. Federation of European Nutrition Societies. Based on session "Controversies about sugar consumption" conducted as part of the 12th European Nutrition Conference (FENS) 2015 in Berlin, Germany, October 21st, 2015. This symposium was supported, in part, by an educational grant from Rippe Lifestyle Institute.

This article belongs to a Supplement sponsored by Rippe Health.

James M. Rippe

jrippe@ rippelifestyle.com

1 Rippe Lifestyle Institute, 21 North Quinsigamond Avenue, Shrewsbury, MA 01545, USA

2 Rippe Lifestyle Research Institute of Florida, 215 Celebration Place, Celebration, FL 34747, USA

3 University of Central Florida, 4000 Central Florida Boulevard, Orlando, FL 32816, USA

4 Department of Metabolism and Nutrition, Institute of Food Science, Technology and Nutrition (ICTAN), Spanish National Research Council (CSIC), C/José Antonio Novais, 10, 28040 Madrid, Spain

$\begin{array}{ll}\text { Abbreviations } \\ \text { 2015 DGAC } & \begin{array}{l}\text { 2015 Dietary Guidelines Advisory } \\ \text { Committee }\end{array} \\ \text { AHA } & \begin{array}{l}\text { American Heart Association } \\ \text { CHD }\end{array} \\ \text { Coronary heart disease } \\ \text { EFSA } & \text { European Food Safety Administration } \\ \text { FDA } & \text { Food and Drug Administration } \\ \text { HFCS } & \text { High-fructose corn syrup } \\ \text { fMRI } & \text { Functional magnetic resonance imaging } \\ \text { NRCT } & \text { Non-randomized controlled trial } \\ \text { RCT } & \text { Randomized controlled trial } \\ \text { SACN } & \text { Scientific Advisory Committee on Nutrition } \\ & \text { in England } \\ \text { SSBs } & \text { Sugars-sweetened beverages } \\ \text { T2D } & \text { Type 2 diabetes } \\ \text { VLDL } & \text { Very low density lipoproteins } \\ \text { WHO } & \text { World Health Organization } \\ \text { YFAS } & \text { Yale Food Addiction Scale }\end{array}$

The consumption of added sugars and their putative effects on various conditions such as obesity [1-3], risk factors for coronary heart disease (CHD) [4-9], diabetes (T2D) [1013] and metabolic syndrome continue to stimulate considerable controversy [14-18].

In addition to active debate within the academic and nutrition professional communities, numerous articles have been written in the popular press, often containing inflammatory headlines and frequently failing to accurately portray modern scientific understandings of the role of added sugars in human nutrition. Headlines such as "Pure, White and Deadly" [19] or "Death by Sugar" [20] or "Sugar, Drastic Measures" have frequently been written. The prestigious New York Times devoted a cover story to their magazine entitled "Sweet and Vicious" [21] related to sugars 
consumption and posed the question "Is Sugar Toxic?" Even prestigious medical journals such as the British Medical Journal have posted articles on its Web site with the inflammatory headline "Sugar is the New Tobacco" [22].

While it has been argued that added sugars consumption, in general, is associated with increased risk of various metabolic diseases, much of the focus has been on the fructose component of many sugars which is contained in roughly equal proportions to glucose in the two leading sources of added sugars in the human diet, namely sucrose and high-fructose corn syrup (HFCS) which is also called "isoglucose" in Europe [23].

Even though sugar (sucrose) has been part of the human diet for millennia, it did not attract much attention from nutrition critics until the 1970s. In 1972 and again updated in 1986 and 2012, John Yudkin's book "Pure, White and Deadly: How sugars are killing us and what we are doing to stop it" was one of the first to suggest nutritional differences between simple sugars and complex carbohydrates [25]. Yudkin posed that sugars had adverse effects even when consumed at levels typical of the human diet.

Modern controversies about sugars appear to have started in the early 2000s. One article that garnered considerable attention was published in 2004, when Bray and Popkin wrote a commentary in the American Journal of Clinical Nutrition suggesting a temporal correlation between increased use of HFCSin the USA and rising rates of obesity [24]. Bray and Popkin posed the hypothesis that "consumption of HFCS in beverages may play a role in the epidemic of obesity." Even though the authors cautioned that they were only raising a hypothesis, and that temporal associations do not establish cause and effect, it quickly was misinterpreted as fact by many members of the media, some internet commentators and even some physicians and scientists.

In the 1980s and 1990s, a series of scientific papers by Reavan and Reiser focused attention on the fructose component of sucrose and HFCS as posing particular problems related to heart disease and metabolic syndrome. Many of the arguments that were promulgated by these two investigators and others were addressed in a 1993 fructose monograph edited by Forbes and Bowman "Introduction to the health effects of dietary fructose," which was published as a Supplement to the American Journal of Clinical Nutrition [26]. This monograph concluded "on the basis of currently available information there is little basis for recommending increased or decreased use of fructose in the general food supply or in products or special dietary use."

A considerable amount of scientific research launched since 2004 has focused on potential relationships between fructose-containing sugars and the obesity epidemic and other related health problems. It should be noted that some portion of the research conducted in this time frame compared pure glucose to pure fructose [27, 28], neither of which is consumed in isolation in any appreciable degree in the human diet. Other research utilized fructose-containing sugars in amounts far greater than people can generally consume in real-world settings [16]. Numerous epidemiologic studies and review articles have also been published in this time frame suggesting a link between sugars consumption, particularly in the form of sugars-sweetened beverages (SSBs), and various adverse metabolic consequences [1, 3, 4, 29-32].

Recently, various scientific and health organizations have joined in this debate by recommending upper limits of sugars consumption far lower than typically consumed by individuals in the industrialized world. The World Health Organization (WHO) [33], Scientific Advisory Committee on Nutrition in England (SACN) [34] and the American Heart Association (AHA) [35] have all proposed dramatically reducing upper limits of sugars consumption to levels of $10 \%$ of calories consumed, or less. The 2015 Dietary Guidelines Advisory Committee (2015 DGAC) [36, 37] also recommended the reduction of upper limit of no more than $10 \%$ of calories from added sugars. This recommendation from the 2015 DGAC also formed the basis for the Food and Drug Administration (FDA) in the USA recommending an upper limit of added sugars consumption of no more than $10 \%$ of calories and proposing a rule listing added sugars as a separate line item on the nutrition facts panel [38].

Many of these recommendations have been opposed by members of the scientific community as not encompassing the totality of available science, particularly from randomized controlled trials or prospective cohort studies. Furthermore, other scientific organizations such as the European Food Safety Administration (EFSA) [39] found no harm, and even some benefit, in fructose consumed up to $25 \%$ of calories, while the Institute of Medicine Carbohydrate Report also found no harm in fructose-containing sugars when consumed at less than $25 \%$ of calories [40] It is also important to emphasize that physical activity has an impact on the metabolic handling of fructose; thus, nutritional considerations should be put in the context of overall lifestyle habits and practices [41-43].

In this contentious environment, a group of experts in various aspects of metabolism convened at the 12th European Nutrition Conference, FENS 2015 in Berlin, Germany, to conduct a session entitled "Controversies about sugar consumption: state of the science." The intent of this symposium was to summarize recent scientific evidence related to the relationship between sugars consumption and various metabolic, physiologic and neurologic sequelae. The articles contained in this supplement are based on presentations made at this conference.

The first paper in this supplement by Sievenpiper and colleagues presents results from systematic reviews and 
Fig. 1 Hierarchy of evidence in evidence-based medicine. () Prof. Dr. John Sievenpiper, with permission

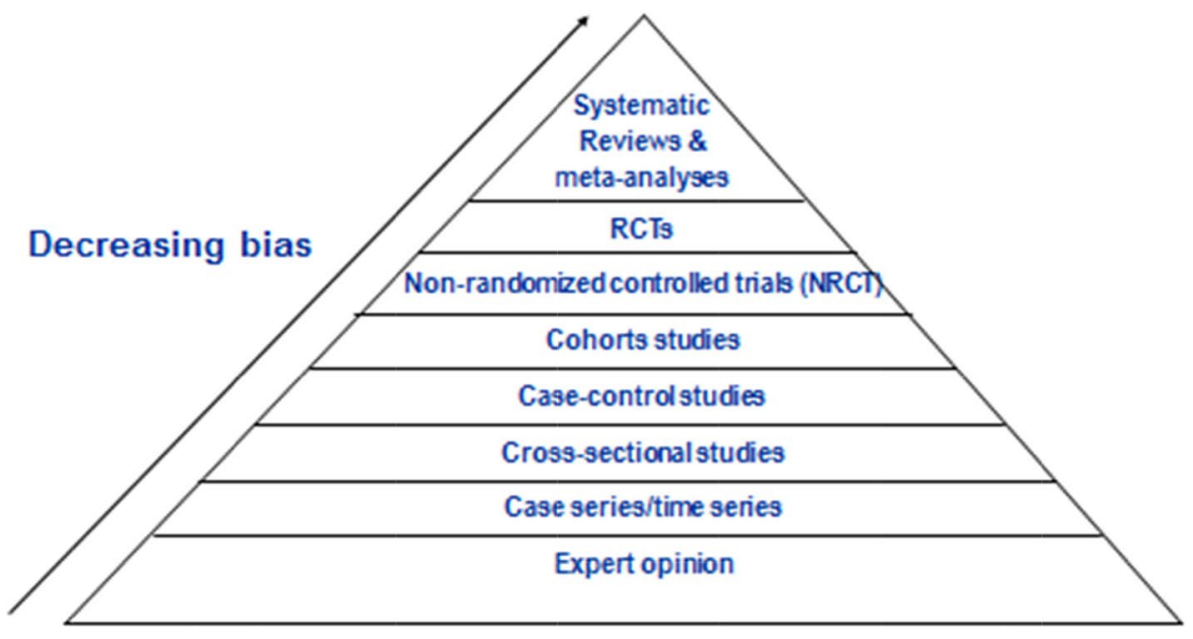

meta-analyses related to obesity and diabetes largely conducted within their research group. Sievenpiper started by exploring the hierarchy of evidence in research trials as outlined in guidelines from England and the USA [44] (see Fig. 1).

As depicted in this figure, the top half of the pyramid showing the least likelihood of bias includes cohort studies, non-randomized controlled trials (NRCT), randomized controlled trials (RCTs) and systematic reviews and metaanalyses. Sievenpiper et al. describe prospective cohort studies published by members of their research group or others involving sugars and weight change, diabetes risk, hypertension risk, gout risk and CHD risk. They conclude that there is little evidence suggesting that sugars consumption within the normal range of human consumption [in the USA, over $87 \%$ of the population had estimated intakes of added sugars $\leq 25 \%$ of total calories which equates to $\leq 92$ grams (day)] [45] leads to increased risk of these metabolic consequences with the sole exception of gout risk. The authors suggest that SSBs may pose more risk than other sources of added sugars, but caution that the relationship is only seen in extreme quantiles analyses with few exceptions, the effect sizes are low $(\mathrm{RR}<1.3)$ and the significance is greatly attenuated by adjustment for energy. Furthermore, residual confounding may exist since consumers of SSBs eat more calories, exercise less, smoke more and have a poor dietary pattern. The authors further remind us that many different foods may contribute to weight change and cite a paper by Mozaffarian et al. [46] which demonstrates that SSB consumption falls behind potato chips and potatoes (particularly French Fries) and is similar to processed and unprocessed red meat with regard to association with weight gains.

The authors provide a review of different types of controlled trials including "substitution" trials, "addition" trials and ad libitum trials with regard to added sugars. They note that the contribution of fructose-containing sugars is difficult to separate from other factors which contribute to the epidemic of obesity and cardiometabolic disease. Furthermore, they argue that any effect of sugars on these risk factors is highly dependent on energy balance and nutrient adequacy. They caution that attention needs to remain focused on reducing overconsumption of all caloric intake including those high in added sugars, whole promoting healthier dietary patterns and increasing physical activity.

Rippe and Angelopoulos in their article "Sugars, Nonnutritive Sweeteners, Obesity and Cardiovascular Disease" present data from RCTs utilizing various levels of HFCS, sucrose, fructose and glucose both from their research laboratory and those of others related to obesity and cardiovascular disease risk factors. These authors remind us that heart disease and stroke remain dominant causes of mortality in both the USA and Europe.

Their article begins with a presentation of theoretical concerns for why differences in metabolism of fructose and glucose in the liver could potentially lead to adverse metabolic effects. It has long been known that fructose and glucose are handled differently in the liver [47]. Over $90 \%$ of ingested fructose is cleared on first pass and metabolized in the liver. A small amount of the fructose taken up by the liver may be converted in the process of de novo lipogenesis into fatty acids (on the order of 1-5\%). These fatty acids are converted to triglycerides in hepatocytes and are released into the systemic circulation complexed with the VLDL.

Several aspects of metabolism of fructose in the liver are important to emphasize. Multiple studies have demonstrated that approximately $50 \%$ of the fructose is converted into glucose and a substantial portion of metabolized fructose appears to be directly stored as glycogen in the liver (approximately $15 \%$ ) [46, 47]. Additionally, about $25 \%$ of fructose is converted into lactate. Thus, only a minor portion of the oral fructose is converted into fatty acids (on the order of 1-5\%) [47-49]. Although this is a minor pathway, 
it has been postulated by some investigators to potentially play a role in the development of fructose-induced hepatic steatosis, particularly when large doses of fructose are administered.

Rippe and Angelopoulos report that experiments conducted in their laboratory at dosage levels between the 25th and 90th percentile population consumption level of fructose have not shown any lipid abnormalities, with the sole exception of triglycerides which often rise when levels above $20 \%$ of calories in added sugars are consumed. Rippe and Angelopoulos further report that there are no differences between sucrose and fructose with regard to energy-regulating hormones or appetite. They note that in the USA, an average increase of 474 calories per person has occurred between 1970 and 2010, but that only $7 \%$ of this increase comes from all added sugars combined [50]. The authors also report no adverse effects on blood pressure from sugars consumed within the normal levels of human consumption in studies lasting up to 10 weeks and no increased risk of obesity, although a slight weight gain occurred at levels between 90 and $95 \%$ population consumption. In addition, no adverse effect on risk factors for diabetes or the metabolic syndrome and no differences between HFCS, sucrose, fructose and glucose with regard to hypothalamic blood flow were found in these studies.

The article by MacDonald focuses on the relationship between sugars and insulin resistance and diabetes. MacDonald presents data that insulin resistance and blood glucose levels are related to a variety of other metabolic conditions including dyslipidemia, CHD, hypertension, hyperinsulinemia and T2D. MacDonald notes that the proposed linkages linking sugars consumption to diabetes provide a mixed picture. Some animal studies have suggested this linkage exists as have some econometric analyses [10, 11]. Animal studies, however, may not translate well into humans, and econometric studies are considered to be a weak form of evidence. As noted by the author, the epidemiologic literature in this area is mixed as is evidence from RCTs. Some studies have suggested that high levels of fructose consumption (between 210 and $280 \mathrm{~g}$ of fructose/day) may increase liver fat and produce hepatic insulin resistance. As noted by the author, a study by Johnston et al. [51] in 32 overweight men with central adiposity showed that when these individuals were in energy balance, fructose and glucose had no effect on liver fat content. With overfeeding, however, fructose and glucose both increased liver fat content.

MacDonald points out evidence reviewed in the SACN report [38] stating that studies provide "no consistent evidence of an association between diets differing in the proportion of sugars in relationship to the incidence of T2D." MacDonald notes that fructose or sucrose consumption may affect insulin sensitivity only at high intakes
(>100 g fructose/day) and that overeating is associated with increased liver and muscle fat, but that the effect is similar for fructose and glucose. There is some evidence of association between SSB consumption and diabetes risk. However, this evidence is confounded by the association between sugars and high energy intake.

The article by Westwater, Fletcher and Ziauddeen tackles the controversial subject of "sugar addiction." The authors pose the question of whether sugar "addiction" truly exists, based on modern science. The authors start by asking whether or not sugar acts like drugs of addiction. The authors review animal data showing that in rat models there is an increased dopamine response to sucrose, but only when it is available intermittently. This increased dopamine response to sucrose also occurs even in shamfed rats, animals that consume the sucrose solution orally, but have it removed immediately via an implanted gastric cannula. This suggests that it is the sweet taste of sucrose rather than its caloric content, which, in combination with the intermittent access, results in the increased dopamine response. They raise the question of whether or not "sugar addiction" exists in human beings or, in more general terms, is there such a thing as more generalized "food addiction."

The authors argue that though foods and drugs may seem to act on the same reward system, the neuroscience of drug addiction appears to be quite different than response to food. Indeed, even the observation that foods and drugs act on the same reward circuits in the brain is not accurate as drugs are thought to hijack the same brain circuits that subserve food reward. They review the Yale Food Addiction Scale (YFAS) raising questions about its reliability and validity [52]. The authors note that dopamine receptor studies in obese individuals have yielded conflicting results as have functional magnetic resonance imaging (fMRI) studies attempting to find a common neural mechanism for obesity, let alone food addiction, in human beings. The authors conclude that while animal models offer proof of concept for the possibility of "sugar addiction," there is little human evidence to support general "food addiction," let alone "sugar addiction." They go on to point out that utilizing the concept of "food addiction" in areas such as diagnosis and treatment, policy change or legislation, or as a mechanism for approaching the obesity crisis all offer severe limitations.

Scientific research, particularly in the area of nutrition, has changed dramatically over the past 10 years. We are in the midst of worldwide pandemics of non-communicable diseases such as obesity and diabetes. CHD remains the leading cause of mortality worldwide. Moreover, the large venue of non-refereed information provided by the internet, in general, and social media, in particular, creates different communications realities than most scientists are equipped 
to handle. Public policy and regulations are at risk for being based on emotion, rather than the highest level of scientific information available.

In the particularly controversial area of added sugars and health, it is important that members of the scientific community base their conclusions on the highest level of science available. We hope that the articles provided in this supplement will provide the scientific community with one such avenue of evidence. We also wish to emphasize as did all of the speakers at the symposium that nutritional issues such as consumption of added sugars need to be placed in the context of overall lifestyle decisions such as weight management and physical activity.

\section{Compliance with ethical standards}

Disclosures J. M. Rippe's research laboratory has received unrestricted grants, and Dr. Rippe has received consulting fees from ConAgra Foods, Kraft Foods, Florida, Department of Citrus, PepsiCo International, The Coca Cola Company, Dr. Pepper/Snapple Group, Corn Refiners Association, Weight Watchers International as well as royalties and editorial office support from CRC Press, Sage Publishing and Springer Publishers.

Open Access This article is distributed under the terms of the Creative Commons Attribution 4.0 International License (http://creativecommons.org/licenses/by/4.0/), which permits unrestricted use, distribution, and reproduction in any medium, provided you give appropriate credit to the original author(s) and the source, provide a link to the Creative Commons license, and indicate if changes were made.

\section{References}

1. Olsen NJ, Heitmann BL (2009) Intake of calorically sweetened beverages and obesity. Obes Rev 10:68-75

2. Malik VS, Schulze MB, Hu FB (2006) Intake of sugar-sweetened beverages and weight gain: a systematic review. Am J Clin Nutr 84:274-288

3. Malik VS, Popkin BM, Bray GA, Despres JP, Willett WC, Hu FB (2010) Sugar-sweetened beverages and risk of metabolic syndrome and type 2 diabetes: a meta-analysis. Diabetes Care 33:2477-2483

4. Bray GA (2012) Fructose and risk of cardiometabolic disease. Curr Atheroscler Rep 14:570-578

5. Marckmann P (2000) Dietary treatment of thrombogenic disorders related to the metabolic syndrome. Br J Nutr 83(Suppl 1):S121-S126

6. Bray GA, Popkin BM (2013) Calorie-sweetened beverages and fructose: what have we learned 10 years later. Pediatr Obes 8:242-248

7. Feig DI, Soletsky B, Johnson R (2008) Effect of allopurinol on blood pressure of adolescents with newly diagnosed essential hypertension. JAMA 300:924-932

8. Nguyen S, Choi H, Lustig R, Hsu C (2009) Sugar-sweetened beverages, serum uric acid, and blood pressure in adolescents. J Pediatr 154:807-813

9. Rippe JM, Angelopoulos TJ (2015) Fructose containing sugars and cardiovascular disease. Adv Nutr 6:430-439
10. Basu S, Yoffe P, Hills N, Lustig RH (2013) The relationship of sugar to population-level diabetes prevalence: an econometric analysis of repeated cross-sectional data. PLoS One 8:e57873

11. Goran MI, Ulijaszek SJ, Ventura EE (2013) High fructose corn syrup and diabetes prevalence: a global perspective. Glob Public Health 8:55-64

12. DiNicolantonio JJ, O'Keefe JH, Lucan SC (2015) Added fructose: a principal driver of type 2 diabetes mellitus and its consequences. Mayo Clin Proc 90:372-381

13. Sievenpiper JL, Tappy L, Brouns F (2015) Fructose as a driver of diabetes: an incomplete view of the evidence. Mayo Clin Proc 90:984-988

14. Rippe JM, Angelopoulos TJ (2015) Sugars and health controversies. What does the science say? Adv Nutr 6(Suppl):493S-503S

15. Lustig RH (2010) Fructose: metabolic, hedonic, and societal parallels with ethanol. J Am Diet Assoc 110:1307-1321

16. White JS (2013) Challenging the fructose hypothesis: new perspectives on fructose consumption and metabolism. Adv Nutr 4:246-256

17. Klurfeld D, Foreyt J, Angelopoulos T, Rippe J (2013) Lack of evidence for high fructose corn syrup as the cause of the obesity epidemic. Int J Obes 37:771-773

18. Rippe J, Angelopoulos T (2013) Sucrose, high fructose corn syrup and fructose, and their potential health effects: What do we really know? Adv Nutr 4:236-245

19. Bray GA (2010) Fructose: pure, white, and deadly? Fructose, by any other name, is a health hazard. J Diabetes Sci Technol 4:1003-1007

20. Death by Sugar (2014) How the sweet killer is fuelling the biggest health crisis of our time. Maclean's. http://www.macleans. $\mathrm{ca} /$ society/health/death-by-sugar-the-biggest-health-crisis-ofour-time/. Accessed 16 July 2015

21. Is sugar toxic? (2011) New York Times magazine. http://www. nytimes.com/2011/04/17/magazine/mag-17Sugar-t.html?_r=0. Accessed 16 July 2015

22. Is Sugar the New Tobacco? (2013) The BMJ Blog. http://blogs. bmj.com/bmj/2013/03/15/balaji-ravichandran-sugar-is-the-newtobacco/. Accessed 16 July 2015

23. White J (2008) Straight talk about high-fructose corn syrup: what it is and what it ain't. Am J Clin Nutr 88(suppl):1716S-1721S

24. Bray GA, Nielsen SJ, Popkin BM (2004) Consumption of highfructose corn syrup in beverages may play a role in the epidemic of obesity. Am J Clin Nutr 79:537-543

25. Yudkin J (1972) Pure, white, and deadly. HarperCollins Distribution Services, New York

26. Glinsmann WH, Bowman BA (1993) The public health significance of dietary fructose. Am J Clin Nutr 58:820S-823S

27. Teff KL, Grudziak J, Townsend RR, Dunn TN, Grant RW, Adams SH (2009) Endocrine and metabolic effects of consuming fructose- and glucose-sweetened beverages with meals in obese men and women: influence of insulin resistance on plasma triglyceride responses. J Clin Endocrinol Metab 94:1562-1569

28. Stanhope KL, Schwarz JM, Keim NL, Griffen SC, Bremer AA, Graham JL, Hatcher B, Cox CL et al (2009) Consuming fructose-sweetened, not glucose-sweetened, beverages increases visceral adiposity and lipids and decreases insulin sensitivity in overweight/obese humans. J Clin Invest 119:1322-1334

29. Lustig RH (2013) Fructose: it's "alcohol without the buzz". Adv Nutr 4:226-235

30. Malik VS, Popkin BM, Bray GA, Despres JP, Hu FB (2010) Sugar-sweetened beverages, obesity, type 2 diabetes mellitus, and cardiovascular disease risk. Circulation 121:1356-1364

31. Ruxton CH, Gardner EJ, McNulty HM (2010) Is sugar consumption detrimental to health? A review of the evidence 1995-2006. Crit Rev Food Sci Nutr 50:1-19 
32. Woodward-Lopez G, Kao J, Ritchie L (2011) To what extent have sweetened beverages contributed to the obesity epidemic? Public Health Nutr 14:499-509

33. World Health Organization (2008) The global burden of disease: 2004 update. World Health Organization, Geneva

34. Scientific Advisory Committee on Nutrition (2014) Draft carbohydrates and health report. June 26-Sept 1. (http://www.sacn. gov.uk/)

35. Johnson RK, Appel LJ, Brands M, Howard BV, Lefevre M, Lustig RH, On behalf of the American Heart Association Nutrition Committee of the Council on Nutrition, Physical Activity and Metabolism and the Council on Epidemiology and Prevention et al (2009) Dietary sugars intake and cardiovascular health, a scientific statement from the American Heart Association. Circulation 120:1011-1020

36. Report of the Dietary Guidelines Advisory Committee on the Dietary Guidelines for Americans (2015) US Department of Agriculture, Center for Nutrition Policy and Promotion. Washington, DC

37. McGuire S (2016) Scientific Report of the 2015 Dietary Guidelines Advisory Committee. U.S. Department of Agriculture and Health and Human Services, 8th edn. Washington, DC. Available at http://health.gov/dietaryguidelines/2015/guidelines/

38. Food Labeling: Revision of the Nutrition and Supplement Facts Labels; Supplemental Proposed Rule To Solicit Comment on Limited Additional Provisions A Proposed Rule by the Food and Drug Administration on 07/27/2015. http://www.federalregister. gov/articles/2015/07/27/2015-17928/food-labeling-revision-ofthe-nutrition-and-supplement-facts-labels-supplemental-proposed-rule-to

39. Agostoni C, Bresson JL, Fairweather-Tait S (2011) Scientific opinion on the substantiation of health claims related to fructose and reduction of post-prandial glycaemic responses (ID 558) pursuant to Article 13(1) of Regulation (EC) no 1924/2006. EFSA J 9:2223-2238

40. Institute of Medicine (U.S.). Panel on Macronutrients, Institute of Medicine (U.S.). Standing Committee on the Scientific Evaluation of Dietary Reference Intakes (2005) Dietary reference intakes for energy, carbohydrate, fiber, fat, fatty acids, cholesterol, protein, and amino acids. Chapter 6-Dietary carbohydrates: Sugars and starches. National Academies Press, Washington, DC
41. Katzmarzyk PT, Leon AS, Wilmore JH, Skinner JS, Rao DC, Rankinen T, Bouchard C (2003) Targeting the metabolic syndrome with exercise: evidence from the HERITAGE Family Study. Med Sci Sports Exercise 35:1703-1709

42. Johnson RJ, Murray R (2010) Fructose, exercise, and health. Curr Sports Med Rep 9:253-258

43. Egli L, Lecoultre V, Theytaz F, Campos V, Hodson L, Schneiter P, Mittendorfer B, Patterson BW, Fielding BA, Gerber PA, Giusti V, Berneis K, Tappy L (2013) Exercise prevents fructoseinduced hypertriglyceridemia in healthy young subjects. Diabetes 62:2259-2265

44. Hierarchy of evidence in evidence based medicine. http://www. sign.ac.uk/guidelines/fulltext/50/annexb.html. http://www.cnpp. usda.gov/Publications/NutritionInsights/Insight38.pdf. http:// www.nice.org.uk/niceMedia/pdf/GDM_Chapter7_0305.pdf

45. Marriott BP, Fink CJ, Krakower T (2014) Worldwide consumption of sweeteners and recent trends. In: Rippe JM (ed) Fructose, high fructose corn syrup, sucrose and health. Springer Science, New York

46. Mozaffarian D, Hao T, Rimm EB, Willett WC, Hu FB (2011) Changes in diet and lifestyle and long-term weight gain in women and men. New Engl J Med 364:2392-2404

47. Tappy L, Le KA (2010) Metabolic effects of fructose and the worldwide increase in obesity. Physiol Rev 90:23-46

48. Sun SZ, Empie MW (2012) Fructose metabolism in humanswhat isotopic tracer studies tell us. Nutr Metab 9:89

49. Hellerstein MK, Schwarz JM, Neese RA (1996) Regulation of hepatic de novo lipogenesis in humans. Annu Rev Nutr 16:523-557

50. US Department of Agriculture, Economics Research Service (2013) Calories: average daily per capita calories from the US food supply, adjusted for spoilage and other waste. Loss-adjusted food availability data

51. Johnston RD, Stephenson MC, Crossland H, Cordon SM, Palcidi E, Cox EF, Taylor MA et al (2013) No difference between high fructose and high glucose diets on liver tricylglycerol or biochemistry in healthy overweight men. Gastroenterology 145:1016-1025

52. Gearhardt AN, Corbin WR, Brownell KD (2009) Preliminary validation of the Yale Food Addiction Scale. Appetite $52: 430-436$ 